\title{
Chicanas: sujetos en traducción
}

\section{Marina FE \\ Universidad Nacional Autónoma de México}

La narrativa de las escritoras chicanas como Sandra Cisneros puede considerarse posmoderna al mismo tiempo que feminista en la medida en que se trata de una "revisión" y desconstrucción de las representaciones culturales de las mujeres chicanas y mexicanas. Es también una literatura crítica que se ubica en una de las fronteras de la cultura occidental, en la frontera entre dos culturas hegemónicas, la estadounidense y la mexicana, cuyos discursos dominantes pone en cuestión.

Este ensayo pone el énfasis en las nociones de frontera y de traducción, particularmente en el caso de estas escritoras cuya actitud crítica y feminista es un gesto de resistencia frente a los paradigmas culturales y sociales. Se trata de una literatura que es en sí misma una forma de traducción y de performance.

PALABRAS CLAVE: chicana, frontera, traducción, revisión, performance, mascarada, Sandra Cisneros.

The narrative of chicana women writers like Sandra Cisneros can be considered postmodern and feminist to the extent that it is both a "revision" and a deconstruction of the cultural representations of chicana and Mexican women. It is also a critical literature produced in one of the frontiers of Western culture, in the border of two hegemonic cultures, the American and the Mexican, questioning their dominant discourses. This essay emphasizes the notions of border and translation, particularly in the case of these writers whose critical and feminist attitude is a gesture of resistance to cultural and social paradigms. It is a literature that is in itself a form of translation and a performance.

KEY WORDS: chicana, border, translation, revision, performance, masquerade, Sandra Cisneros.

Deslenguadas. Somos los del español deficiente. We are your linguistic nightmare, your linguistic alienation, your linguistic mestisaje, the subject of your burla. Because we speak with tongues of fire we are culturally crucified. Racially, culturally and linguistically somos huérfanos —we speak an orphan tongue.

Gloria Anzaldúa, Borderlands 


\section{Fronteras}

La literatura chicana puede considerarse posmoderna en la medida en que se trata de una literatura crítica que se ubica en una de las fronteras de la cultura occidental, en la frontera entre dos culturas hegemónicas, la estadounidense y la mexicana, cuyos discursos dominantes pone en cuestión. Desde ahí, desde la frontera, surge una actitud crítica a partir, por ejemplo, del hecho mismo de recurrir a las dos lenguas en un mismo texto, creando un texto híbrido que es ya un gesto de resistencia frente a los paradigmas dominantes. Se trata así de una escritura que es en sí misma una forma de traducción y que es producto de una experiencia de dos mundos y dos ideologías vividas, por así decirlo, desde el margen.

En The Politics of Postmodernism, Linda Hutcheon pone énfasis en el carácter crítico del arte posmoderno antes que en lo que para otros autores, como Fredric Jameson, sería su aspecto apologético, de complicidad o complacencia con el orden establecido - un posmodernismo "light", vacío de sentido, que anula toda posibilidad de cambio y promueve una visión catastrofista. Ella prefiere definirlo como un "posmodernismo paradójico": "de complicidad y crítica, de reflexividad e historicidad, que al mismo tiempo inscribe y subvierte las convenciones e ideologías de las fuerzas culturales y sociales dominantes del mundo del siglo veinte" (1995: 2). ${ }^{1} \mathrm{Y}$ es ese carácter paradójico de la posmoderna literatura chicana y la posición "fronteriza" que ocupa frente, o entre, dos culturas, lo que vale la pena rescatar.

Hablar de frontera, desde la frontera, implica en este caso no solamente el referente inmediato de la línea que divide a México de Estados Unidos, sino todos aquellos factores que afectan la vida personal, familiar y comunitaria de quienes han tenido que irse "del otro lado" por razones que todos conocemos, pero que conservan, y se empeñan en conservar, lazos culturales, sociales y afectivos con nuestro país. Así, ser chicano implica necesariamente un posicionamiento a partir de la frontera, línea divisoria real e imaginaria que desubica, desplaza, descoloca a estos mexicanos que aquí ya no tienen lugar y que allá son Otros: espaldas mojadas, gente de color, ciudadanos de segunda, "mexican-americans... " Pero también puede pensarse en la frontera como figura, tal vez como metáfora o metonimia, de esa línea virtual que está ahí sólo para dividir, para separar y para ser atravesada, aunque nunca nadie puede quedarse en ella, sino siempre de uno u otro lado. También en la literatura chicana la palabra se traslada y se descentra, y es siempre "otra", como sucede con la palabra traducida.

La experiencia de frontera es entonces la experiencia de los límites: geográficos, culturales, sociales, ideológicos, raciales, corporales, reales e imaginarios. Pero también, sobre todo en el caso de los escritores y artistas, puede ser la experiencia de la transgresión de dichos límites, de la subversión ante lo prohibido, de la apropiación de lo ajeno, de la invención y el rescate de una identidad. No se trata sin embargo de

${ }^{1}$ Todas las traducciones son mías. 
una identidad fija y estable ya que la frontera, como punto de referencia, sólo define la división, la separación permanente entre una y otra cosa, la no-pertenencia, la desnaturalización. Sin embargo, esta inestabilidad, esta des/identidad, no es necesariamente negativa ya que, en términos culturales, puede ser y ha sido fuente de una literatura y un arte de gran riqueza. Por otra parte, es justamente ese desplazamiento, esa translación o traducción cultural, lo que hace posible la transgresión mediante, por ejemplo, la re/visión de los mitos fundacionales de ambas culturas, pero especialmente de la mexicana, para construir otra identidad, atravesada por la diferencia, en constante movimiento, en proceso. ${ }^{2}$

Para las escritoras chicanas como Sandra Cisneros y Gloria Anzaldúa escribir es traducir esta experiencia vivida a flor de piel, hablar de esta identidad desde la ficción, o más bien desde esa otra frontera que separa la realidad de la ficción y que abre la posibilidad de experimentar y transgredir otras fronteras, en este caso las literarias.

\section{Revisiones}

Si la frontera es límite o margen, las mujeres chicanas son doblemente marginales (por ser chicanas y por ser mujeres) y escriben desde esos márgenes con la intención de traspasar las fronteras de clase, raza y género en busca de lo que Norma Alarcón llama "géneros prófugos" (outlaw genres). Pero, ¿cómo escribir desde el margen? Hacerse esta pregunta implica un reto, el reto de decir de otra manera, desde otro sitio que no está definido ni es definitivo, desde un afuera de la cultura oficial, experimentando, distanciando, desnaturalizando y negociando otras fronteras. Una estrategia para hacerlo es la revisión y la reescritura de ciertos mitos culturales que desde una perspectiva chicana y feminista proponen una nueva manera de interpretar y reinventar la realidad: "Es así que, dentro de una cultura como la nuestra, si una quiere cortar de cuajo con ésta al adquirir una 'voz propia', es necesario revisar y apropiarse de las creencias metafísicas más valoradas" (Alarcón, 1993: 25).

Una de las figuras míticas recuperadas por las escritoras chicanas es La Malinche, identificada tradicionalmente por los mexicanos como la traidora y la "chingada" y, por extensión, a la manera fundacional de la Eva bíblica, identificada también con todas las mujeres, particularmente aquellas que se rebelan contra la autoridad patriarcal transgrediendo con ello los valores e intereses de una comunidad. ${ }^{3}$ Malinalli, bautizada o

\footnotetext{
2 "Borders are set up to define the places that are safe and unsafe, to distinguish us from them. A border is a dividing line, a narrow strip along a steep edge. A borderland is a vague and undermined place created by the emotional residue of an unnatural boundary. It is in a constant state of transition. The prohibited and forbidden are its inhabitants. Los atravesados live here: the squint-eyed, the perverse, the queer, the troublesome, the mongrel, the mulatto, the half-breed, the half-dead; in short, those who cross over, pass over, or go through the confines of the "normal"' (Anzaldúa, 1987: 3).

3 “ [... ] the male Myth of Malintzin is made to see betrayal first of all in her very sexuality, which makes it nearly impossible at any given moment to go beyond the vagina as the supreme site of evil
} 
traducida con el nombre de Marina, se ve obligada a ser la "lengua", la intérprete entre dos hombres poderosos, Motecuhzoma y Cortés, y hacer posible el diálogo entre dos mundos, dos imperios, dos universos lingüísticos absolutamente distintos. Su persona misma se convierte entonces, por así decirlo, en la frontera entre ambas realidades, en la mediadora de los sentidos de una y otra parte, cómplice de ambas y por eso mismo traidora: "Cada vez que traducía de ida y vuelta entre los dos mundos, desde las dos historias, la Malintzin inventaba una verdad hecha de mentiras; una verdad hecha para un tercero que estaba aún por venir" (Echeverría, 1994: 134).

Pero es justamente por su papel subversivo, así como por su función de traductora, que Malintzin es recuperada por las chicanas como la mujer que es capaz de enfrentarse a otra cultura, de intervenir entre diferentes discursos y al mismo tiempo de hablar en nombre propio, superando las fronteras impuestas desde afuera y desde adentro.

En su papel de traductora ella actúa como mediadora entre dominios culturales e históricos antagónicos. Si pensamos que el lenguaje es siempre en algún sentido metafórico, entonces cualquier discurso, oral o escrito, puede llegar a traicionar cuando se percibe que va más allá de la repetición de lo que la comunidad considera como el concepto, imagen o relato "verdadero" y/o "auténtico" (Alarcón, 1993: 23-24).

Identificada en su papel de víctima con la figura de La Llorona que ha perdido a sus hijos o quizás a sus hijas, la Malinche, símbolo de la mestiza, aparece de manera oblicua pero evidente en el cuento de Sandra Cisneros que da nombre a su colección, "Woman Hollering Creek" (1991); o bien podríamos decir que la Llorona se transforma en la Malinche cuando deja de llorar y empieza a gritar, como veremos en el cuento. Estructurado en una serie de fragmentos, este relato presenta a un personaje femenino que de entrada nos parece bastante conocido: Cleófilas Enriqueta de León Hernández, que va a casarse para luego seguir al esposo al otro lado. Como en un cuento de hadas, o más bien en una telenovela, Cleófilas ha encontrado a su príncipe azul, aunque su padre ha vaticinado que algún día "his daughter would rise her hand over her eyes, look south, and dream of returning..." (43). La historia es por todos conocida: ella se casa, se va a Texas, tiene un bebé, el marido se emborracha y la maltrata... pero no así el desenlace.

Antes de casarse, y a pesar de vivir como soltera rodeada de hombres (nos enteramos después que es huérfana de madre), en su pueblo natal Cleófilas cuenta con amigas, tías y madrinas que se visitan, van al cine o ven telenovelas, prácticamente la única fuente para hacerse de una educación sentimental: "Tú o Nadie [... ] El título de la telenovela favorita. La hermosa Lucía Méndez tiene que soportar todo tipo de problemas del corazón, separación y traición, y amar, siempre amar a pesar de todo, porque eso es lo más importante, y ¿viste a Lucía Méndez en el comercial de aspirina Bayer? — ¿no estaba preciosa?" (44-45).

until proven innocent by way of virginity or virtue, the most pawnable commodities around" (Alarcón, 1983: 183). 
Narrada aparentemente en tercera persona, la historia de pronto incorpora otras voces en diálogos sin ninguna marca tipográfica y también en una primera persona que no se sabe bien quién es, cambiando incluso el tiempo de la narración de pasado a presente. El relato se divide en fragmentos, pasa de México y los preparativos de la boda a Seguín, Texas, donde se encuentra el arroyo de la Gritona (nombre que se dice le pusieron los indios). Cleófilas ya tiene un bebé y su única compañía son las vecinas, Soledad y Dolores, ambas solas y tristes a causa de los hombres que las abandonaron. En el cuento se describen los momentos, el primero y los subsecuentes, en que su marido la golpea para después llorar arrepentido, cosa que no pasa en las telenovelas.

Y en poco tiempo, Cleófilas se descubre a sí misma decepcionada de este hombre al que se siente atada y que seguramente le pone ios cuernos con otra. El único lugar para ir, como no sea la casa de las vecinas, es el arroyo que ejerce sobre ella una extraña fascinación: “¿Es La Llorona, la mujer que llora? La Llorona que ahogó a sus propios hijos. Quizás es por La Llorona que le pusieron al arroyo ese nombre... " (51). Más adelante, el marido le pega arrojándole el libro de Corín Tellado, único escape a su condición de subordinada y que aquí se convierte en un instrumento de violencia en su contra. Así, convertida en víctima, y debido a su impotencia, Cleófilas parece identificarse con La Llorona y no sabe cómo convencer al marido de que la deje ir al médico para no poner en riesgo su segundo embarazo.

Al darse cuenta de la situación de Cleófilas, una enfermera chicana se pone de acuerdo con una amiga para ayudarla a escapar de él y regresar a México. En la última parte, Felice la lleva a ella y a Juan Pedrito en su pick-up a San Antonio, y al cruzar el arroyo pega un grito superlativo: "Cada vez que cruzó ese puente hago eso. Por el nombre, sabes. Mujer que grita. Pues, yo grito. Dijo esto en un español mezclado con inglés y se rió. ¿Alguna vez notaste, continuó Felice, que nada de por aquí tiene nombre de mujer? De veras. A menos de que sea la Virgen. Supongo que sólo eres famosa si eres virgen" (55). El nombre del arroyo adquiere entonces para Cleófilas un significado diferente pues ya no se trata de La llorona sino de la Gritona, la mujer fuerte y autónoma que toma sus propias decisiones y se niega a seguir representando el papel de víctima. En cierto sentido, recupera las características positivas de Malintzin que si "traiciona" es para salvar el pellejo, para dejar de llorar y tener una voz propia, un grito liberador.

\section{Traducir/se}

Es necesario también ubicar a las escritoras chicanas dentro de un contexto feminista, ya que el feminismo y el posmodernismo comparten el mismo afán de lo que Hutcheon llama "desdoxificación", es decir, la crítica de los dogmas ideológicos que hemos heredado del capitalismo económico y del humanismo cultural en las sociedades patriarcales. Así, las escritoras chicanas, en su mayoría feministas, se han dado a la tarea de explorar nuevos senderos, nuevas estrategias narrativas que critiquen o desconstruyan 
las representaciones tradicionales de lo femenino desde una perspectiva de género, pero también de clase y raza, planteando, junto con otras escritoras pertenecientes a las "minorías" de Estados Unidos, la necesidad de escribir una "literatura de mujeres de color", "una de las ideas más novedosas surgidas en el contexto imperialista angloeuropeo" (Alarcón, 1983: 45).

Para Gloria Anzaldúa, en su importante libro Borderlands/La frontera. The New Mestiza, la frontera es "una herida abierta", y es también el origen de otras heridas, la metáfora de esas dolorosas heridas del cuerpo y del alma que representan el ser chicana, ser lesbiana, ser mujer en la frontera, desde la frontera, del otro lado de las fronteras. Más allá de la geografía, se trata aquí de una condición existencial que surge de la experiencia de la marginalidad, de la diferencia, de la otredad vivida en carne propia, a flor de piel y en profundidad. Desde esa posición de exterioridad puede construirse o traducirse una nueva identidad: fronteriza, fragmentada, en proceso. De acuerdo con Judith Butler, para Anzaldúa el sujeto es múltiple, en un constante proceso de traducción cultural: "Así, lo que ella propone es que sólo al existir en el modo de traducción, constante traducción, es como tenemos la posibilidad de producir una comprensión multicultural de las mujeres o, sin duda, de la sociedad" (2004: 228).

De esta manera, para las chicanas resulta también fundamental la noción de mestizaje, esa fusión que pone en contacto por lo menos a dos culturas, apropiándolas pero también transformándolas, "rescribiéndolas". Es posible entonces hacerse de una identidad a partir de un lenguaje subversivo, de una lengua híbrida, de una "traducción" que resiste de manera creativa y a veces juguetona a los discursos dominantes y sus paradigmas: "Con imágenes domo mi miedo, cruzo los abismos que tengo por dentro. Con palabras me hago piedra, pájaro, puente de serpientes arrastrando a ras del suelo todo lo que soy, todo lo que algún día seré" (Anzaldúa, 1987: 71). Ese proyecto escriturai/existencial, esa traducibilidad, surge para Gloria Anzaldúa de una toma de conciencia: "una nueva conciencia mestiza, una conciencia de mujer. Es una conciencia de la frontera" (77).

La idea de la nueva mestiza con una conciencia de mujer se relaciona directamente con la noción de frontera y de cómo traducir y traducirse a partir de la frontera. El énfasis aquí es en la ambigüedad, en las contradicciones como constitutivas de una identidad en constante movimiento, abierta a la tolerancia y a lo incluyente, para romper con todas las formas de opresión. Así, en el caso de las chicanas escribir y traducir son una suerte de performance lo mismo que un constante ir y venir entre culturas. El término "performance" puede entenderse en el sentido teatral de representación, de actuación por parte de un actor: un texto se vuelve a hacer presente, vuelve a cobrar vida, a actuar cuando alguien lo lee. Pero también es posible describir dicho performance como un proceso de traducción y autotraducción, como una mascarada, es decir, como una desconstrucción de las representaciones culturales de la Mujer llevándolas al límite, al exceso, a la sobrerrepresentación. ${ }^{4}$

4 "The masquerade, conceived as a double strategy of acceptance and denial of femininity, is, thus, 
Desde la perspectiva de las teorías poscolonial y feminista, así como los "queer studies", los conceptos de mímica o pantomima (mimicry) y mascarada suelen aplicarse al fenómeno de la traducción (o bien la traducción suele servir como ejemplo y metáfora de ciertos procesos culturales), ya que esta especie de reflejo especular que se pretende que sea la traducción es también, de alguna manera, una suerte de teatralización (o performance, si se quiere), pues, a la manera del fetiche, el texto traducido imita al original y al hacerlo cuestiona y desvaloriza las formas y la autoridad o "verdad" de su discurso. A partir del desplazamiento del sentido, del movimiento de una lengua a otra, de una a otra cultura y de uno a otro individuo, tiene lugar una suerte de dispersión que "desnaturaliza" al texto original. Se trata de una reescritura subversiva: "Este paradigma de la traducción como manipulación de textos cuyo significado se deriva de su transformación" (Godard, 1990: 92). Barbara Godard recurre a los ejemplos de la cita y la parodia para mostrar en qué consiste dicha "repetición intercultural" que resulta en una alteración del orden de las palabras y de los niveles de lenguaje: "Como la cita y otras formas de repetición, la parodia es una puesta en abismo, un 'espejeo' de los orígenes de la figuración realista $\mathrm{y}$, en consecuencia, tiene una función metaficcional" (93). Así, la traducción crítica procura apropiarse del lenguaje y darle otra forma, transformarlo, descentrarlo, mostrando la diferencia al producir un efecto de extrañamiento, de desfamiliarización ante el texto (y el discurso) original. Y aquí el traductor no pretende ser invisible ni que su trabajo duplique el original como una copia transparente; busca más bien mostrar la diferencia, hacerse notar como el responsable de una recodificación crítica.

Un ejemplo puede encontrarse en "Little Miracles, Kept Promises", donde Sandra Cisneros propone la revisión de la virgen de Guadalupe que va a ser reapropiada y "traducida" desde otra perspectiva, eliminando su carácter sublime de madre pura y virginal y transgrediendo así la iconización tradicional de la Iglesia católica para transformarla en una figura híbrida. "Little Miracles, Kept Promises" es un conjunto de textos de ésos que suelen acompañar a los exvotos (milagritos) en una iglesia agradeciendo a los santos los favores recibidos. Cada uno de estos textos está firmado por un "autor" diferente, con o sin apellido, con una simple inicial, en nombre de una familia, etcétera. Unos están dirigidos a la Virgen y otros al Santo Niño de Atocha, San Martín de Porres, San Antonio de Padua, al Niño Fidencio, a Don Pedrito Jaramillo Healer of Los Olmos, a los Mighty Poderosos, Blessed Powerful Ones (incluyendo en este grupo al gran general Pancho Villa, al virtuoso John Kennedy, and blessed Pope John Paul. Amen. ) y también a los santos africanos como Obatalá, Yemayá, Ochún, Orunda, Ogun, Eleguá y Shangó). Cada breve texto cuenta una historia, pero cada lector tendrá que inventarse el "cuento" correspondiente. El último texto, el más largo, es el de Chayo, quien le ofrece a la virgen su trenza de pelo agradeciéndole no estar embarazada. Este texto intercala en cursivas los comentarios de la madre y otras

a means toward subverting all notions of a 'natural' femininity... then gender becomes a performance rather than an essence" (Robinson, 1991: 120). 


\section{G CHICANAS: SUJETOS EN TRADUCCIÓN}

mujeres de la familia que muestran de una manera muy económica pero efectiva cómo el discurso femenino tradicional es inculcado de madres a hijas, particularmente en relación con la maternidad.

No está bien pasar tanto tiempo sola.

¿Qué hace ahi adentro sola? No se ve bien.

Chayito, ¿cuándo te casas? Mira a tu prima Leticia. Es más chica que tú... ¿Cuántos niños quieres tener cuando seas grande?

Cuando yo sea una mamita...

Ya cambiarás. Vas a ver. Espérate a conocer al hombre de tu vida

(Cisneros, 1991: 126).

Descubrimos el terror de Chayo ante su posible embarazo, pero sobre todo su rechazo a cumplir ese rol que no es el que ella siente que tiene destinado: "No me importaría ser papá. Por lo menos un papá todavía puede ser artista, puede querer algo en lugar de alguien, y eso a nadie le parece egoísta" (127). Le confiesa a la Virgencita que antes no creía en ella porque la culpaba de la situación de su madre y su abuela "y todo lo que las madres de nuestras madres han tenido que soportar en nombre de Dios" (127). Con un lenguaje muy simple, el reclamo es sin embargo contundente, ya que se niega a aceptar el rol tradicional de mujer que se sacrifica en silencio y que es el que la institución religiosa impone a las mujeres católicas (y a otras). Así, Chayo recupera a la Guadalupana convirtiéndola en un personaje en el que sí se reconoce:

Ya no María la suave, sino nuestra madre Tonantzín [... ] Cuando descubrí que tu verdadero nombre es Coatlaxopeuh [... ], Teteoinnan, Toci, Xochiquetzal, Tlazolteotl, Coatlicue, Chalchiuhtlicue, Coyolxauhqui, Huixtocihuatl, Chicomecoatl, cuando pude verte como Nuestra Señora de la Soledad, Nuestra Señora de los Remedios, Nuestra Señora del Perpetuo Socorro, Nuestra Señora de San Juan de los Lagos [... ] Cuando pude verte en todas tus facetas, al mismo tiempo el Buddha, el Tao, el verdadero Mesías, Yahvé, Alá, el Corazón del Cielo, el Corazón de la Tierra, el Señor de lo Cercano y lo Lejano, el Espíritu, la Luz, el Universo, pude quererte $\mathrm{y}$, finalmente, aprender a quererme (128).

Gracias a este nuevo sincretismo, el mito de Guadalupe recupera de alguna manera su significado prehispánico, pero la virgen también se convierte en una deidad poderosa que reúne a todas las deidades posibles y de cierta manera las asimila en una Diosa topoderosa en contraposición a los dioses masculinos de las sociedades patriarcales: ya no es exclusivamente la madre de Dios sino el mismísimo Dios.

Sandra Cisneros critica, desconstruye y resignifica estos mitos culturales fuertes, así como también lo hace con el mismo humor e ironía en otros cuentos de la misma colección con figuras menores pero igualmente representativas de la sociedad de Estados Unidos, como en el caso de "The Marlboro Man" y hasta de las muñecas Barbie en "Barbie-Q". Para lograr romper con los grandes relatos heredados, estos nuevos "mitos" posmodernos de las mestizas chicanas son, a diferencia de los mitos 
tradicionales, inestables, flexibles, paródicos y siempre abiertamente críticos de las ideologías racistas, clasistas y sexistas dominantes tanto de Estados Unidos como del resto del mundo, globalizado o no.

\section{Obras citadas}

ALARCÓN, Norma. 1993. "Traduttora. traditora; una figura paradigmática del feminismo de las chicanas". Debate Feminista, año 4, vol. 8, septiembre. México. . 1983. "Chicana's Feminist Literature: A re-vision through Malintzin / or Malintzin: putting flesh back on the object". Eds. Cherrie MoraGA y Gloria ANZALDÚA, This Bridge Called My Back: writings by radical women of color. Nueva York: Kitchen Table. (Women of Color Press)

AnZALdúA, Gloria. 1987. Borderlands/La Frontera. San Francisco: Aunt Lute Books.

BUtLER, Judith. 2004. Undoing Gender Nueva York / Londres: Routledge.

Cisneros, Sandra. 1991. Woman Hollering Creek. Nueva York: Vintage Books.

ECHEVERRÍA, Bolívar. 1994. "Malintzin, la lengua". Ed. Margo Glantz, La Malinche, sus padres y sus hijos. México: UNAM, FFL.

GODARD, Barbara. 1990. "Theorizing Feminist Discourse/Translation”. Eds. Susan BASSNETT y André LEFEVERE, Translation: History and Culture. Londres: Punter.

HutCHeON, Linda. 1995. The Politics of Postmodernism. Londres / Nueva York: Routledge.

LionNet, Françoise. 1995. Postcolonial Representations. Ithaca / Londres: Cornell University Press.

MCCRACKEN, Ellen. 1999. New Latina Narrative. Tucson: The University of Arizona Press.

RoBINSON, Sally. 1991. Engendering the Subject. Gender and Self-Representation in Contemporary Women's Fiction. Albany: State University of New York Press. 